\title{
URBAN WIND TURBINES AND THE POSSIBILITY OF THEIR USE IN SLOVAKIA
}

\author{
Daniel Probala \\ Institute of Earth Resources, Faculty BERG, Technical University of Košice, Park Komenského 19, 04200 Košice, \\ Slovakia, daniel.probala@gmail.com \\ Bianka Sabolová \\ Institute of Earth Resources, Faculty BERG, Technical University of Košice, Park Komenského 19, 04200 Košice, \\ Slovakia, bianka.probalova@gmail.com \\ Matúš Jeňo \\ Institute of Earth Resources, Faculty BERG, Technical University of Košice, Park Komenského 19, 04200 Košice, \\ Slovakia, matus.jeno@tuke.sk
}

\begin{abstract}
Keywords: small wind power devices, urban wind turbines, wind speed,intensity of turbulencet Abstract: Small wind turbines are specially designed for the built environment and can be placed on buildings, embedded in buildings or freestanding on the ground next to buildings. This means that the turbine is designed for the wind in the built environment and withstands the impact of wind and turbulence and that the shape and size of the turbines have been designed to meet the visual conditions of surrounding buildings with the environment in mind. Its purpose is to generate clean emission-free energy for homes, offices, schools, and the like. Thanks to this simple and increasingly popular technology, turbine owners can produce their energy and save not only money but also the environment.
\end{abstract}

\section{Introduction}

Small wind turbines are available on the world market in all sorts of concepts, performances, and dimensions. The number of installed small wind devices in the country depends not only on conditions such as relief or the actual wind conditions. But also the policy of the state regarding electricity buyout, public awareness, subsidies during the construction, as well as market and technical assistance and the availability of such equipment and spare parts. Globally, growth in sales of small wind devices is annually increasing. In 2013 was recorded 870,000 installed small wind devices. A global leader is China, which has 625,000 installed units. By a significant gap followed by the US and European countries, led by Britain. The total installed capacity of small wind devices in 2014 reached $730 \mathrm{MW}$, which compared to 2013 represents an increase of $10.9 \%$.

\section{Urban wind turbines}

With advances in the technologies of wind turbines, it is possible to use small and micro wind turbines to overcome the unfavorable state of the wind in built-up areas. The emergence of urban wind turbines is given by new technologies and advances in the construction of turbines, plus favorable financial incentives offered by the government, given the ever-increasing energy prices. There is also growing public interest in wind turbines, despite the fact that the public is not sufficiently familiar with this issue [1]. Experts also add that the emergence of urban wind turbines is necessary due to the shift in the approach of centralized production of energy to heat and power generation directly at the place of consumption [3]. But they also point out that the use of known technologies in wind turbines, in the end, might not lead to full exploitation of the potential of turbines. It is, therefore, need for more detailed research and development of new typologies of HAWT - horizontal axis wind turbine and VAWT - vertical axis wind turbine designs that will implement more efficient generators able to cope with the characteristics of the wind in urban areas [4].

Urban wind turbines vary from large wind turbines in many ways. From the perspective of the blade design, small wind turbines require different aerodynamic profile than large wind turbines due to the differences in peripheral speed in proportion to the wind speed. Blades of large wind turbines are more advanced in terms of aerodynamic design than small wind turbines, which are mostly affected by a coefficient of performance of wind turbine. The peripheral speed of a small wind turbine has a direct impact on the transmission system and energy production, and therefore it requires a gearbox. Directly driven systems are more reliable and require less maintenance. Also, the energy of small wind turbines and systems regulating speed are different from large wind turbines, using mechanically controlled systems of slope and deflection, which are different from large wind turbines with an electronic control system. Besides, small wind turbine towers are relatively high, as they need to achieve unimpeded flow of the wind over the windward side of the obstacles.

Urban wind turbines will always be at a disadvantage with the installation in unsuitable places, compared to large wind turbines, due to lower heights in densely populated urban areas. It is also not clear whether urban wind turbines might be standardized in built-up areas due to variable wind direction. Wind flow in this low altitude is influenced 
by local conditions such as turbulence intensity. Therefore, there are more suitable locations for the progress of the development of urban wind turbines in rural areas and coastal areas - where the sea breeze is present, and suburban areas - where there are fewer barriers to the flow [1].

There are a number of technical issues that need to be addressed in the development of wind turbine systems for built-up areas, which are [4]

1) System type - static, integrated in a building / facility, deflection system, with / without convector and / or diffuser,

2) System attributes - self-triggering, safe, low noise, weak vibration, durable construction, minimal maintenance, lightweight, high performance,

3) Placement - aesthetics, strength of building / infrastructure, electromagnetic interference of existing power facilities, space for other equipment such as monitoring system.

Another aspect is the difficulty of obtaining small wind turbines compared with large ones. Old wind turbines with low capacity can be redesigned and used in the built environment, but in order to maximize energy production from integrated wind turbine in the built environment the following points should be taken into account:

- turbines should preferably be placed on large buildings with extensive roof,

- determine what type and model of turbines are best to use for the selected building and site,

- deploy more turbines on the same site, if possible,

- examine whether the building and its surroundings are suitable for the placement of urban wind turbines,

- acquire the consent for the placement of turbines in the area,

- determine the visual impact on the surroundings - the movement of the blades can produce a visual distortion in the area,

- concentration of turbines placement in certain areas,

- ensure that the turbines are marked in spatial development plans and that this development is respected by all interested parties,

- devote sufficient attention to the aesthetic aspect of integration - the turbines need to be well visually integrated into the building or site.

Regarding the integration of wind turbines within the built environment, there are four main types of integration. Wind turbines integrated within the built environment are classified based on their position in relation to buildings [5]. The main objective is to capture fast winds at low turbulence of flow. And therefore may be urban wind turbines either:

- freestanding on a very high base in the built environment (wind turbines near buildings),
- mounted on the surface of buildings, such as on roofs (building mounted wind turbines),

- fully integrated into the building,

- within the pipes in the building.

\subsection{Buildings integrated wind turbines - BIWT}

Dutton [2], described wind turbines near buildings as freestanding wind turbines, which are able to work near buildings and benefit from an enhanced flow of wind caused by surrounding buildings. They can be added to existing urban areas or incorporated in its entirety into the design of new built-up areas where the whole project is tailored to their placement. Although wind turbines near buildings can provide more energy than wind turbines mounted on buildings, the price per kilowatt is usually quite high (compared with medium / large wind turbines) due to the need to cover the costs for the foundations of the turbine, tower, and wiring.

An example of this type is small freestanding turbine in Mile and Ecology Centre in London and the wind turbine at the BP station, Wandsworth, also in London, which are $6 \mathrm{~kW}$ turbines with a blades diameter of 5.5 meters. Another example of this type is the installation of three $15 \mathrm{~kW}$ wind turbines within the project ZEBRA (Zero Emission Building Renewing Alnwick), where the estimated power is $60,000 \mathrm{kWh}$ per year.

According to the report WINEUR [12], this type of integration in between the built environment is usually being realized in the open spaces and areas of the built environment such as school playgrounds and parks.

\subsection{Building mounted wind turbines - BMWT}

According to the Royal Institute of British Architects (RIBA), wind turbines mounted on buildings are gaining the most public attention. However, one of the main obstacles, associated with this type is obtaining building permits, but there are a couple of examples of permitted wind turbines mounted on buildings. These devices are more likely to contribute to the supply of electricity within the built environment. Wind turbines are mounted on buildings as physically connected to buildings, where the building plays the role of the vertical pillar for the placement of the wind turbines for the use of required wind flow [2].

Given that the built environment is complex, the urban context could have a significant impact on the flow on the tops of roofs and most likely will be very dynamic, turbulent and include a vertical component. Even at the same roof, the conditions can vary dramatically from one place to another.

According to the project WINEUR [12], the most influencing parameter of wind flow over the roof, is a shape of the roof. Experts also pointed out the importance of the impact of roof shape on the local wind flow. They also mentioned the need to investigate the influence of different shapes of roofs on wind speed and turbulence intensity and how it would be possible to increase the 
URBAN WIND TURBINES AND THE POSSIBILITY OF THEIR USE IN SLOVAKIA

Daniel Probala; Bianka Sabolová; Matúš Jeňo

efficiency of energy production from wind turbines placed on buildings. In addition to selecting the optimal place for attachment, a building should be suitable for the placement of wind turbines and should also provide a reduction in vibration and noise [2].

Projects, where the existing buildings were fitted with urban wind turbines, are not always feasible or returnable, but if the design of the building was counting with the possible implementation of wind turbines from the beginning, the results might be better. Concerns about noise, vibration and energy yield can be eliminated, if there is properly conducted evaluation of the wind and application of the correct wind turbine at optimum mounting location. It is said that the wind turbine with a vertical axis of rotation, type Triple-Helix Quietrevolution (QR) (Figure 1), is ideal for urban environments. It is rated at $6 \mathrm{~kW}$, produces $10,000 \mathrm{kWh} /$ year at average wind speeds, it is free standing at approximate height of 14 meters with a span of 3 meters. If it is placed on a building, sufficient height for mounting is 8 meters. Moreover, it is profitable, which makes it attractive for business and building developers.



Figure 1 Wind turbine type Triple-Helix Quietrevolution [10]

In the future it will be likely to see the combined systems of wind turbines and photovoltaic modules fully integrated into the design of the roof. For the conceptual design of the wind turbine mounted on a building, the turbine should have flexible construction design to be easily anchored on a top of the roof or an edge of the building. Therefore, they developed the concept of Darrieus VAWT called Crossflex (Figure 2), which has a flexible system of blades, uses light frame system, which extends the airflow and improves visual integration into buildings. It also has a modular design thanks to which it can be placed on the corners of buildings for generating useful energy level.

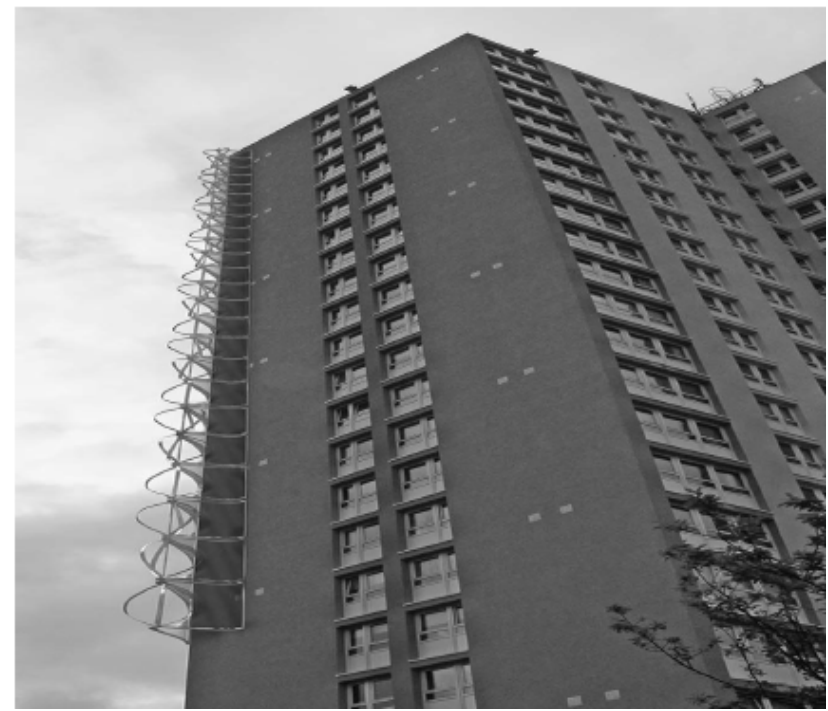

Figure 2 Crossflex concept and its mounting [9]

Even though is a placement of each wind turbine specific, there are a few basic procedures to be followed:

- for mounting HAWT on flat roofs, the turbine should be placed near the center of the roof at $35-50 \%$ of the height of the building,

- if you cannot place the turbine sufficiently high with relation to the spatial plan, it is preferable to use a VAWT, which can also withstand a high level of turbulence intensity,

- the building, on which the wind turbine is integrated should be higher than the surrounding buildings by at least $30-50 \%$ of the height of surrounding buildings,

- full assessment of the wind should be done with due regard to the wind direction and its effect on the orientation of the building,

- the minimum wind speed at the site should be more than $5 \mathrm{~m} / \mathrm{s}$ and turbulence intensity less than $10 \%$,

- appropriate supporting structure and crane access are also important,

- measures must be taken to ensure sufficient strength of the building structure, which is not as easily reachable in renovated buildings.

\subsection{Building augmented wind turbines - BAWT}

Wind turbines fully integrated into buildings are those wind turbines capable of producing concentrated energy from aerodynamically shaped buildings. In this case of the integration of wind turbine is the shape of the building used to direct the wind directly into the turbine. The shape of the building serves as a support for integrated wind turbines and as a wind accumulation place. Here is the essential role of the architect in the design of the building, which must be based on aspects relating to aerodynamics. Successful installation of BAWT requires a comprehensive 
URBAN WIND TURBINES AND THE POSSIBILITY OF THEIR USE IN SLOVAKIA

Daniel Probala; Bianka Sabolová; Matúš Jeňo

knowledge of aerodynamics of buildings, wind energy, wind energy transformations and assessment of effective costs. The construction of the building may require some adjustments based on the assessment of the wind flow tests in the wind tunnel and CFD simulations. There is a growing interest among architects to integrate wind turbines into their projects and buildings forming into the shape of a funnel. Number of new projects that were based on the principle of aerodynamic buildings to enhance the performance of integrated wind turbines. For example, Bahrain World Trade Centre, Pearl River Tower in China, Strata SE1 in London - all with fully integrated wind turbines in the building.

Bahrain World Trade Centre is designed to collect and compress the wind flow between the two towers, where is the wind turbine with a horizontal axis of rotation placed (Figure 3). Narrowing of the Bahrain World Trade Centre, results in increased wind speed at the location of the turbine up to $30 \%$, resulting in the supply of electricity from turbines in the range of $11-15 \%$ of the needs of the building [6]. The same effect of narrowing is implemented on Pearl River Tower, where the building has four large openings, approximately $3 \times 4$ meters wide. The facade is shaped so as to reduce the forces of resistance and optimize the rate at which wind flows through these openings. These openings act as pressure valves for the building.

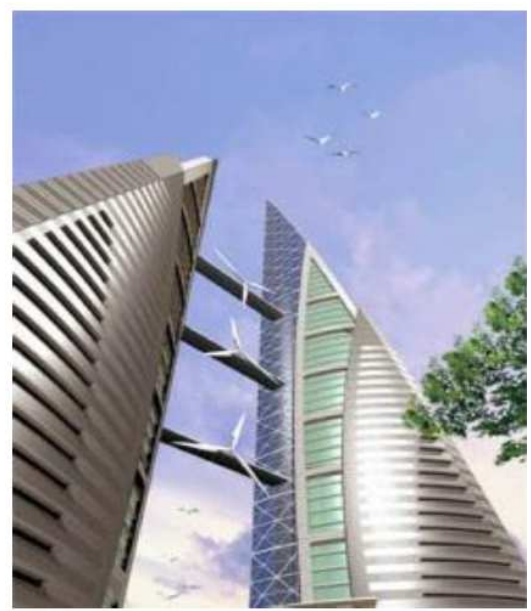

Figure 3 Bahrain World Trade Centre [6]

Altechnica of Milton Keynes patented the concept, that demonstrates how can be the implemented shape of the roof for the placement of wind turbines.

The system is designed for installation on the crest of the roof or on the top of curved part of the roof. The rotors are incorporated in the structure resembling a cage which are covered with the profile. This profile can be equipped with photovoltaic cells, where the rotors are placed on the top of the curved roof. This effect should lead to concentration of wind in a manner similar to flow around the car hood. The advantage of this system is that it does not interfere with the visual observation for the observer and appears as an integrated part of the building. Also, the system is suitable for installation on existing buildings, with appropriate wind.

Concepts integrating large wind turbines with a vertical axis of rotation in aerodynamically shaped buildings are still under development and appear only in the thoughts of designers and proposals of futuristic buildings. However, buildings like Bahrain World Trade Centre or Pearl River Tower are indeed built, but it is very difficult to acquire the information, which show the performance of the integrated wind turbines in detail, so that we can assess their effectiveness. So far it is impossible to assume that projects such as these will become common in the built environment, given the wind turbines, which are not always visually appropriate. For this reason, the successful design of wind turbines must be built to bring the value for the building itself.

\subsection{Diffuser augmented wind turbines - DAWT}

Another group of turbines are diffuser-augmented wind turbines, which are covered to increase the concentration of wind (Figure 4). According to [3], unlike conventional wind turbines, DAWT were originally developed for integration into the built environment. The main advantage of DAWT is mainly that they are mostly HAWT and blades are fully enclosed in a casing. Casing is designed for horizontal flow management, where the pressure difference between inlet and outlet of the unit is used to drive the turbine. A form of closure, input, output and installation of spoilers play an important role in obtaining energy from installed wind turbine installed.

During the development, since '70s turbine blades were placed inside the housing profile and prototypes were developed at the University of Rijeka, in Croatia, where the stated yield of such an arrangement of the turbine is increased by $60 \%$ as compared to freestanding wind turbines. This is attributed to accelerating effect of the profile that allows the turbine to operate at lower wind speeds, as it collects more wind from different sides and leads it directly to the turbine blades.

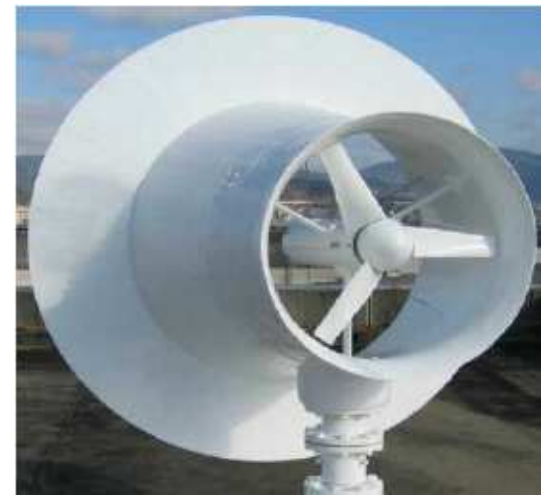

Figure 4 Example of the diffuser-augmented wind turbine [6]

However, at high wind speeds there is a risk of excessive stress of the blades, which was resolved by introducing hydraulically controlled openings for 
discharging air from the turbine housing, which is activated when the pressure in the housing is too high. The main problem remains in the high initial cost of the equipment, due to the use of special material for the manufacture of housing, but it might remain ignored in the long run, considering the energy yield.

The use of cover for the blades has several advantages [3]: blade,

- improved security in the event of failure or loose

- greater energy yield than with conventional wind turbines due to higher pressure differences,

- integrates easily into architectural design,

- visually less intrusive.

On the other hand, it should be noted that if the wind speed exceeds $16 \mathrm{~m} / \mathrm{s}$, the effect of the shaft will not be as significant. It is therefore necessary to consider economic factors, before it is decided to use diffuser-augmented wind the turbines, since they are usually more expensive than conventional wind turbines.

\section{The legislation of using small wind devices in Slovakia}

Among the equipment for the production of electricity through wind power as a renewable energy source, belong undoubtedly small wind installations. According to the installed capacity, small wind installations are considered as those with power up to $20 \mathrm{~kW}$. On the other hand, the law on the promotion of RES speaks about small energy sources as the equipment for the production of electricity from renewable energy sources with a total installed capacity of $10 \mathrm{~kW}$, while the producers of electricity from small power source are provided with a special preferential privileges regarding the connection of the equipment to the distribution network.

With regard to the placement of small wind installations in built-up areas, it must satisfy a number of legal conditions. First of all, the size of a small wind devices. Small wind plant shall be regarded within the meaning of the Constitution $\S 139 \mathrm{~b}$ point c) of Act no. 50/1976 Coll. on Territorial Planning and Building Code (Building Act) as a simple structure, if its built-up area does not exceed $300 \mathrm{~m} 2$ and $15 \mathrm{~m}$ in height. In this case there is a simplified authorization procedure for placement of small wind devices. A simplified method for authorizing construction means that the construction office will decide on the location of the building (by the decision on the location of the building is the building land determined, the building is placed on it, determining of the conditions for the building placement, determining the requirements for the contents of project documentation and the period of validity of the decision), in this decision it can determine that for realization of the construction, the notification for construction office will suffice. The second variant is a situation, where the conditions for placing are clear, given the conditions in the area, the construction office connects area management on building placement with the building proceedings and issues a decision on the authorization of construction (building permit).

If the wind device exceeds the above-described dimensions, the building permits is required for the construction. Thereafter, a valid certificate of practical completion leads to permanent use authorization of the device, and thus to its entry into service.

Of course, issuance of a decision on the location of the construction as well as subsequent building permit or construction notification is preceded by the fulfilment of a number of requirements that are defined by the Building Act, such as requirements for the protection of nature and landscape and the care of the environment, to ensure compliance of urban solution and architectural design of the building with the surrounding environment and the like, and submission of project documentation.

The most important prerequisite for granting a building permit or construction notification - for a small wind device is the assessment process of the effects of construction on the environment.

Since the law on the assessment of environmental impacts does not distinguish wind devices - power plants according to their performance, the impact assessment applies on all wind devices, which represents a substantial administrative and financial burden for small wind devices. All the above conditions apply to small wind devices that may be located, for example in the garden of family house in built-up areas. There is almost no legislative regulation, regarding the placement of small wind installations on residential buildings.

In every apartment building are common areas of the building. Installation of a small source could cover the annual consumption of electricity consumed in the common areas (lighting, door opener, small circulation pumps and partially lift consumption) using the generated electricity from small wind devices directly, or in combination with energy storage. It would also to ensure emergency lighting of staircases and other common areas (requirement STN 1838, 2001) during a power outage from distribution network, thus increasing the safety of the occupants of the house. It is not necessary to be connected to the distribution system for this type of power supply.

\section{Conclusion}

Summarizing the above mentioned it could be concluded that the installation of small wind installations in built-up areas in Slovakia represents a substantial administrative and financial burden that is more or less insurmountable. In other words, there is an absence of legislation related to their installation in built-up areas.

\section{References}

[1] BAHAJ, A.S., MYERS, L., JAMES, P.A.B.: Urban energy generation: influence of micro-wind turbine 
output on electricity consumption in buildings. Energy and buildings, Vol. 39, No.2, pp. 154-165, 2007.

[2] DUTTON, A.G., HALLIDAY, J.A., BLANCH, M.J.: The Feasibility of Building-Mounted/Integrated Wind Turbines (BIWTs): Achieving their potential for carbon emission reductions. Final Report of Carbon Trust Contract, 2002.

[3] GRANT, A.D., KELLY, N.J.:A ducted wind turbine simulation model for building simulation, Building Services Engineering Research and Technology, Vol. 25, No. 4, pp. 339-349, 2004.

[4] BOOKER, J., MELLOR, P., WROBEL, R., DRURY, D.: A compact, high efficiency contra-rotating generator suitable for wind turbines in the urban environment. Renewable Energy, Vol. 35, No. 9, pp. 2027-2033, 2010.

[5] DANNECKER, R.K.W., GRANT, A.D.:

Investigations of a building-integrated ducted wind turbine module. Wind Energy, Vol. 5, No.1, pp.53-71, 2002.

[6] KILLA, S., SMITH, R.F..: Harnessing Energy in Tall Buildings, Bahrain World Trade Center and Beyond. [Online], Available:

http://global.ctbuh.org/resources/papers/download/464 -harnessing-energy-in-tall-buildings-bahrain-worldtrade-center-and-beyond.pdf [24 Nov 2016], 2008.

[7] The home as micro-power station Part 2 (EcoRefurbishment), [Online], Available: http://whatwhen-how.com/eco-refurbishment/the-home-asmicro-power-station-part-2-ecorefurbishment [22 Nov 2016], 2016.

[8] THANGAVELU, S. K., MUTASHER, S. A., KENNY LAU, Z.H.: Design and flow velocity simulation of diffuser augmented wind turbine using CFD, Journal of Engineering Science and Technology, Vol.8, No.4, pp.372-384, 2013.

[9] MOSTAFAEIPOUR, A.: Productivity and Development Issues of Global Wind Turbine Industry, Renewable and Sustainable Energy Reviews, Vol.14, No.3, pp.48-1058, 2010.

[10] The qr6 Vertical Axis Wind Turbinehttps, , [Online], Available: http://www.quietrevolution.com/ [22 Nov 2016], 2016

[11] Urban wind turbines, Guidelines for small wind turbines in the built enviroment, [Online], Available: http://www.urbanwind.org/pdf/SMALL_WIND_TURBINES_GUIDE _final.pdf [20 Nov 2016], 2007

[12] Wind Energy Integration in the Urban Environment WINEUR, [Online], Available: https://ec.europa.eu/energy/intelligent/projects/sites/i ee-

rojects/files/projects/documents/wineur_summary_sl ides.pdf [10 Sep 2016], 2016

\section{Review process}

Single-blind peer reviewed process by two reviewers. 